\title{
A Survey Of Perceived Barriers And Motivators Towards Exercise Among People With Parkinson's Disease In Malaysia
}

\author{
Alfonsa Choo K.Y. ${ }^{\text {a,b }}$, Rajkumar K.V ${ }^{b}$ \\ ${ }^{a}$ B.E.N Physio, Kuala Lumpur, Malaysia \\ ${ }^{b}$ Faculty of Health and Life Sciences, INTI International University, Nilai, Malaysia.
}

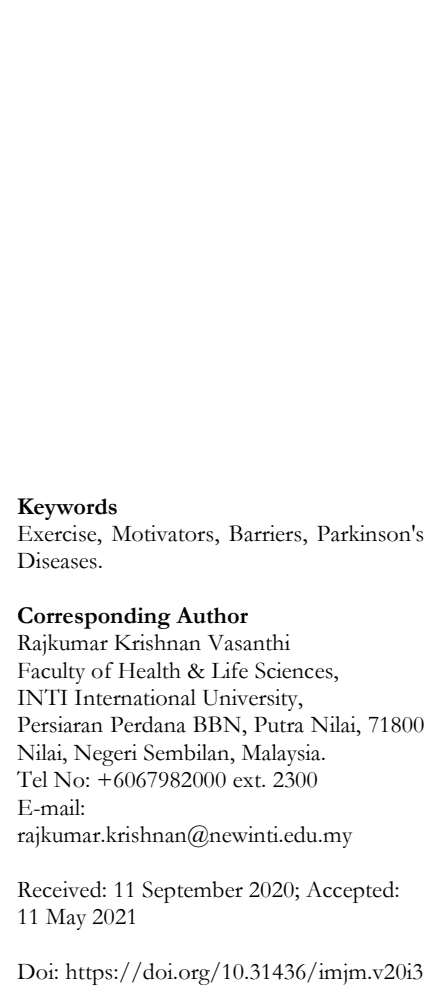

\begin{abstract}
INTRODUCTION: Considerable amount of evidence supports that exercise plays a vital role in maintaining and slowing Parkinson's disease (PD) progression. However, some people with PD have remained sedentary for undefined reasons. Therefore, the perceived barriers and motivators towards exercise among people with PD among Malaysian were investigated. METHODS: A cross-sectional survey was conducted using a self-developed and validated questionnaire distributed to forty-seven people with PD in a nongovernmental organisation to determine exercise barriers and motivators. RESULTS: The exercise motivators in the study were having an exercise instructor (83.0\%), exercise makes them feel healthier and more energetic (83.0\%), and constant encouragement from family and friends $(80.9 \%)$. The exercise barriers reported in this study were fatigue $(40.4 \%)$ fear of falling (34\%), bad weather (38.2\%), and lack of transportation $(31.9 \%)$. CONCLUSION: The study concluded that people with PD exercised because it makes them feel healthier and more energetic. Besides that, having an exercise instructor and being encouraged by family and friends reported being exercise motivators among the people in this study. The exercise barriers reported in this study were fatigue, bad weather, fear of falling, and lack of transportation. These findings should be taken into consideration when developing strategies and health interventions to improve exercise participation for people with PD.
\end{abstract}

\section{INTRODUCTION}

In Malaysia, according to the Ministry of Health in 2019 has projected the number of people with PD will continue to increase from the current approximate 30,000 in the next 20 years due to an increase in elderly populations. PD affects $1 \%$ of the population above 60 years. Exercise has proven to benefit people with PD by preventing disability and improve their quality of life. It is often prescribed alongside medical and surgical management to slow down the progression of PD. Despite the benefits that exercise can bring to people with PD, they are still known to be more physically inactive compared to the general population.

A study that compared between exercisers and nonexercisers showed a significant difference in motivating the people with PD to exercise more ${ }^{1}$ and another study also revealed that group of people with PD who regularly participate in exercise programs were social cohesiveness of exercise groups, perceived psychological effects of exercise such as improved mood, and the physical effects experienced after exercising such as increased energy and improved physical functions. $^{2}$

On the other hand, a study examined the meaning of exercise as well as the barriers and motivators to exercise in a group of active people living with PD. The participants reported that the reason why they adhere to exercise programs was to maintain health and participation in life. ${ }^{3}$ This was consistent with another research that reported that they exercise to retain their identity of being active. ${ }^{4}$ Besides that, having specific 
life goals and self-efficacy were also identified as important motivators to exercise for people with PD.

Having an exercise instructor, exercising in a group shown improvements in physical functioning with exercise and this was the reason to adhere to the exercise program. ${ }^{5}$ The perceived exercise barriers are associated with the undertaking of physical exercise behaviors such as access to fitness facilities. ${ }^{6}$ A crosssectional study examined the perceived barriers towards exercise among people and compared them between the exercise group to a non-exercise group and the exercise barriers reported were fear of falling, lack of time, and low outcome expectations in the non-exercise group. ${ }^{7}$

In a qualitative study, the authors identified that the exercise barriers in people with PD can be partly dependent on cultural and environmental contexts and practices. ${ }^{8}$, even though the motivators identified in the study were similar to other studies. The barriers identified by the study were quite different which included difficulty of diagnosis, lack of informational support, and lack of referral to physiotherapy services. All these barriers were relevant to a developing country like Jordan due to the socioeconomic and poorer health structures.

Although there are existing studies regarding this topic, there is still a need for this study to be done because of limited studies on this topic in a Malaysian context. Besides that, the findings of prior studies may not be relevant to our context because the exercise beliefs, exercise motivators, and exercise barriers may vary due to differences in socioeconomic, cultural, environmental, and health care structures in Malaysia compared to other developed or developing countries.

These differences may lead to different life experiences, mindsets, challenges, and even provision of physiotherapy services, which can influence exercise barriers, and motivators. Hence, there is a clear need to examine the exercise motivators and barriers to exercise participation among people with PD from the Malaysian context, so that strategies can be developed to improve their exercise participation.

\section{METHODOLOGY}

This was a cross-sectional study conducted at a pioneer non-governmental organisation in Malaysia, which represents people with PD. The eligibility criteria comprised of people with PD whose age is 80 years and below with idiopathic Parkinson's Disease and does not have any severe cognitive impairments in mini cog: score of three or more. People with PD who have an unconfirmed diagnosis of PD and suffering from other chronic conditions that can cause severe disability were excluded from the study. Informed consent was obtained from those willing and able to participate in the study. A survey questionnaire which includes demographic profiles like age, duration of PD, gender, race, marital status, residence, and employment status were included followed by 20 items of perceived barriers to exercise (Table 3) and 12 items represent the motivation to exercise (Table: 2) was developed and piloted for its content validity by three experts ( $\mathrm{S}$ $\mathrm{CVI}=0.8645$ ) and subsequently, the reliability was tested using Cronbach's alpha analysis and the reliability was acceptable with an alpha score on perceived barriers as $\alpha=0.858$ and motivators as $\alpha=0.787$. The test -retest correlation was high $(r=0.985)$ for the perceived barriers to exercise. Test-retest correlation was found to be high $(r=0.971)$ for perceived motivators to exercise. The selected forty-seven participants between Jan 2019 to May 2019 have completed the self-administrated survey upon signing the consent. Once the participants have completed the questionnaire, data were collected and analysed.

\section{ETHICAL APPROVAL}

Before conducting the study, permission to conduct the research was obtained from the Faculty ethical committee of The University (INTI/FHLS/RAC/ JAN/2) upon complied with all the relevant national regulations and institutional policies that have followed the tenets of the Declaration of Helsinki.

In the consent form; a brief introduction, objectives of the study, participant selection, methodology of the study, duration, risks, benefits, confidentiality, and 


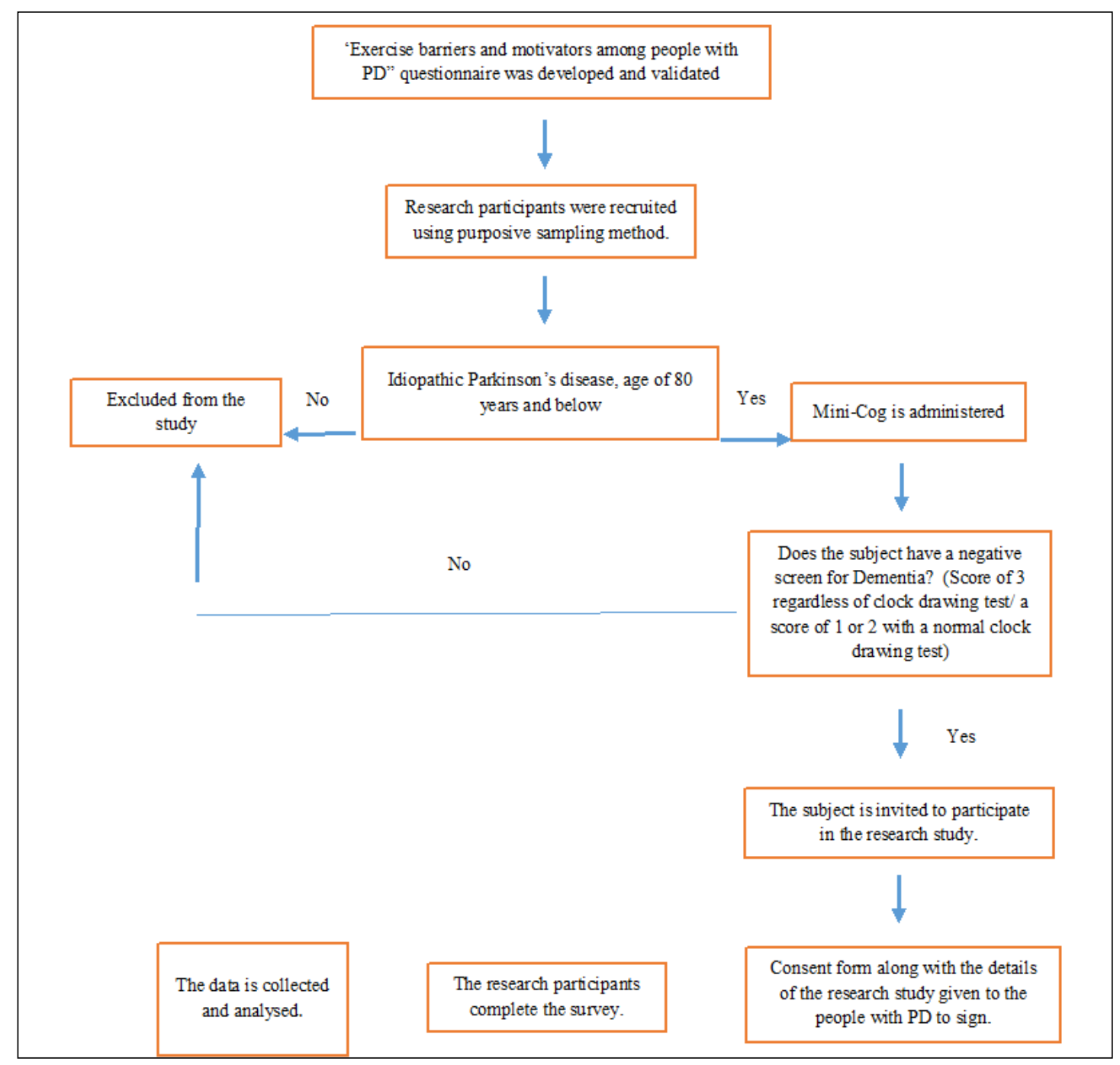

Figure 1: Flow chart for the process and procedure of data collection

rights to refuse or withdraw any time during the study were included and clearly stated for the research participants.

\section{STATISTICAL ANALYSIS}

Data collected on the variables such as age, duration of PD diagnosis, gender, race, marital status, residing location, and employment status of the participants in this study were analysed using SPSS Ver 23.0. Descriptive statistics such as frequency and percentage were calculated to summarise their exercise motivators, and exercise barriers of this study.

\section{RESULTS}

The mean age duration of the research participants in this study was 69 years and the mean diagnosis duration of the research participants in this study was 9 years. A large proportion of the research participants were urban population including Chinese, accounting for $85.1 \%$ of the total research participants, with only $8.5 \%$ and $6.4 \%$ of them being Malays and Indians, respectively. The majority of the research participants were married and unemployed (Table 1).

An overview of the motivators for exercise in people with PD is shown in Table 2. More than two-fifths of the research participants reported that all the possible exercise motivators could be effective in increasing their exercise participation except for one, which is exercising to meet new people. $83.0 \%$ of the research participants agreed that having an appropriate exercise instructor motivates them to exercise, followed by encouragement from family and friends to exercise, which was reported in $80.9 \%$ of the research participants. $74.5 \%$ of the research participants strongly agreed/agreed that they 
Table 1: Sociodemographic characteristics of participants.

\begin{tabular}{|c|c|c|}
\hline & Frequency (n) & Percentage (\%) \\
\hline $\begin{array}{l}\text { Age } \\
\text { Less than } 50 \\
50-59 \\
60-69 \\
70 \text { and above }\end{array}$ & $\begin{array}{c}4 \\
4 \\
25 \\
14\end{array}$ & $\begin{array}{c}8.5 \% \\
8.5 \% \\
54.19 \% \\
29.8 \%\end{array}$ \\
\hline $\begin{array}{l}\text { Duration of PD } \\
5 \text { years and less } \\
6-10 \text { years } \\
\text { More than } 10 \text { years }\end{array}$ & $\begin{array}{c}22 \\
8 \\
17\end{array}$ & $\begin{array}{l}46.8 \% \\
17.0 \% \\
36.2 \%\end{array}$ \\
\hline $\begin{array}{l}\text { Gender } \\
\text { Male } \\
\text { Female }\end{array}$ & $\begin{array}{l}21 \\
26\end{array}$ & $\begin{array}{l}44.7 \% \\
55.3 \%\end{array}$ \\
\hline $\begin{array}{l}\text { Race } \\
\text { Chinese } \\
\text { Malay } \\
\text { Indian }\end{array}$ & $\begin{array}{c}40 \\
4 \\
3\end{array}$ & $\begin{array}{l}85.1 \% \\
8.5 \% \\
6.4 \%\end{array}$ \\
\hline $\begin{array}{l}\text { Marital status } \\
\text { Single } \\
\text { Married }\end{array}$ & $\begin{array}{c}8 \\
39\end{array}$ & $\begin{array}{l}17.0 \% \\
83.0 \%\end{array}$ \\
\hline $\begin{array}{l}\text { Residing location } \\
\text { KL } \\
\text { Selangor }\end{array}$ & $\begin{array}{l}13 \\
34\end{array}$ & $\begin{array}{l}27.7 \% \\
72.3 \%\end{array}$ \\
\hline $\begin{array}{l}\text { Employment status } \\
\text { Employed } \\
\text { Unemployed }\end{array}$ & $\begin{array}{c}4 \\
43\end{array}$ & $\begin{array}{c}8.5 \% \\
91.5 \%\end{array}$ \\
\hline
\end{tabular}

exercise to improve their mood, $83.0 \%$ to feel healthier and more energetic and $72.0 \%$ of them reported that they exercise because it gives them a sense of accomplishment.
It can be seen from Table 3 that fatigue was the barrier that had the highest agreements from the research participants as compared to other exercise barriers, with approximately two-fifths $(40.4 \%)$ of the research participants followed by bad weather $(38.2 \%)$, fear of falling (34\%), and lack of transportation (31.9\%).

\section{DISCUSSION}

Based on the objectives to identify the perceived motivators and barriers towards exercise among people with PD in Malaysia the present study found that the majority of the participants $(>80 \%)$ reported that (a) Having an exercise instructor and (b) Constant encouragement from family and friends can motivate them to exercise more. These findings were consistent with a study on motivators and barriers to exercise in Parkinson's disease, in which the exercise motivators identified also included having an exercise instructor and exercising with a significant, other/spouse. ${ }^{1}$

In another study, the authors also highlighted the importance of exercise instructors for PD patients to remain in an exercise program. According to the

Table 2: Exercise Motivators.

\begin{tabular}{|c|c|c|c|c|c|c|}
\hline \multirow{2}{*}{ Motivators } & \multicolumn{3}{|c|}{ All $(n=47)$} & \multicolumn{3}{|c|}{ All $(100 \%)$} \\
\hline & $\mathrm{D} / \mathrm{SD}$ & NA/ND & $\mathbf{A} / \mathbf{S A}$ & $\mathrm{D} / \mathrm{SD}$ & NA/ND & $\mathbf{A} / \mathbf{S A}$ \\
\hline It improves my mood. & 0 & 12 & 35 & $0.0 \%$ & $25.5 \%$ & $74.5 \%$ \\
\hline $\begin{array}{l}\text { It makes me feel healthier and more } \\
\text { energetic. }\end{array}$ & 2 & 6 & 39 & $4.3 \%$ & $12.8 \%$ & $83.0 \%$ \\
\hline $\begin{array}{l}\text { it gives me a sense of } \\
\text { accomplishment. }\end{array}$ & 7 & 7 & 33 & $14.9 \%$ & $14.9 \%$ & $70.2 \%$ \\
\hline $\begin{array}{l}\text { It makes me feel like I can take } \\
\text { control of my condition. }\end{array}$ & 9 & 12 & 26 & $19.1 \%$ & $25.5 \%$ & $55.3 \%$ \\
\hline $\begin{array}{l}\text { It allows me to meet new people, } \\
\text { particularly people with Parkinson's. }\end{array}$ & 15 & 13 & 19 & $31.9 \%$ & $27.7 \%$ & $40.4 \%$ \\
\hline Group exercise & 7 & 13 & 27 & $14.9 \%$ & $27.7 \%$ & $57.4 \%$ \\
\hline Exercise partner. & 2 & 8 & 37 & $4.3 \%$ & $17.0 \%$ & $78.7 \%$ \\
\hline Exercise instructor. & 5 & 3 & 39 & $10.6 \%$ & $6.4 \%$ & $83.0 \%$ \\
\hline $\begin{array}{l}\text { Constant encouragement by my } \\
\text { doctor or a health care professional. }\end{array}$ & 4 & 7 & 36 & $8.5 \%$ & $14.9 \%$ & $76.6 \%$ \\
\hline $\begin{array}{l}\text { Information regarding the type of } \\
\text { exercises that provided by doctor/ } \\
\text { healthcare professional }\end{array}$ & 3 & 8 & 36 & $6.4 \%$ & $17.0 \%$ & $76.6 \%$ \\
\hline $\begin{array}{l}\text { Encouragement from family and } \\
\text { friends }\end{array}$ & 3 & 6 & 38 & $6.4 \%$ & $12.8 \%$ & $80.9 \%$ \\
\hline $\begin{array}{l}\text { Partner or family members exercise } \\
\text { with me. }\end{array}$ & 3 & 7 & 37 & $6.4 \%$ & $14.9 \%$ & $78.7 \%$ \\
\hline
\end{tabular}

*D/SD: Disagree/Strongly disagree; NA/ND: Neither agree nor disagree; A/SA: Agree/Strongly agree 
Table 3: Exercise Barriers.

\begin{tabular}{|c|c|c|c|c|c|c|}
\hline \multirow[t]{2}{*}{ Barriers } & \multicolumn{3}{|c|}{ All $(n=47)$} & \multicolumn{3}{|c|}{ All $(100 \%)$} \\
\hline & $\mathrm{D} / \mathrm{SD}$ & NA/ND & $\overline{\mathrm{A} / \mathrm{SA}}$ & $\mathrm{D} / \mathrm{SD}$ & NA/ND & $\mathbf{A} / \mathbf{S A}$ \\
\hline I am scared that I will fall & 28 & 3 & 16 & $0.0 \%$ & $59.6 \%$ & $34 \%$ \\
\hline $\begin{array}{l}\text { I have fallen before when exercis- } \\
\text { ing }\end{array}$ & 33 & 6 & 8 & $70.2 \%$ & $12.8 \%$ & $17.0 \%$ \\
\hline $\begin{array}{l}\text { I do not exercise because of the } \\
\text { symptoms of PD }\end{array}$ & 31 & 6 & 10 & $66.0 \%$ & $12.8 \%$ & $21.3 \%$ \\
\hline I feel tired during the day & 20 & 8 & 19 & $42.6 \%$ & $17.0 \%$ & $40.4 \%$ \\
\hline I feel sad all the time & 35 & 5 & 7 & $74.5 \%$ & $10.6 \%$ & $14.9 \%$ \\
\hline It is too painful to exercise & 34 & 5 & 8 & $72.3 \%$ & $10.6 \%$ & $17.0 \%$ \\
\hline I do not have the time to exercise & 38 & 5 & 4 & $80.9 \%$ & $10.6 \%$ & $8.5 \%$ \\
\hline I think I am too old to exercise & 41 & 2 & 4 & $87.2 \%$ & $4.3 \%$ & $8.5 \%$ \\
\hline $\begin{array}{l}\text { I do not think that I am capable of } \\
\text { doing so }\end{array}$ & 40 & 0 & 7 & $85.1 \%$ & $0.0 \%$ & $14.9 \%$ \\
\hline $\begin{array}{l}\text { I am afraid that I cannot hold my } \\
\text { bladder during exercise. }\end{array}$ & 38 & 3 & 6 & $80.9 \%$ & $6.4 \%$ & $12.8 \%$ \\
\hline $\begin{array}{l}\text { I do not think that exercise will } \\
\text { slow down the progression of } \\
\text { Parkinson's. }\end{array}$ & 40 & 3 & 4 & $85.1 \%$ & $6.4 \%$ & $8.5 \%$ \\
\hline $\begin{array}{l}\text { I do not think that it is beneficial } \\
\text { for my condition in any way. }\end{array}$ & 40 & 3 & 4 & $85.1 \%$ & $6.4 \%$ & $8.5 \%$ \\
\hline $\begin{array}{l}\text { I do not have enough information } \\
\text { regarding the type of exercise that } \\
\text { is suitable and safe for me. }\end{array}$ & 30 & 6 & 11 & $63.8 \%$ & $12.8 \%$ & $23.4 \%$ \\
\hline $\begin{array}{l}\text { Lack of available activities to suit } \\
\text { my interest. }\end{array}$ & 30 & 4 & 13 & $63.8 \%$ & $8.5 \%$ & $27.7 \%$ \\
\hline I have nobody to exercise with. & 34 & 4 & 9 & $72.3 \%$ & $6.4 \%$ & $19.1 \%$ \\
\hline $\begin{array}{l}\text { Bad weather prevents me from } \\
\text { exercising. }\end{array}$ & 26 & 3 & 18 & $55.3 \%$ & $6.4 \%$ & $38.2 \%$ \\
\hline $\begin{array}{l}\text { My cultural beliefs prevent me } \\
\text { from exercising. }\end{array}$ & 41 & 4 & 2 & $87.2 \%$ & $9 \%$ & $4.3 \%$ \\
\hline $\begin{array}{l}\text { Lack of transportation prevents } \\
\text { me from exercising. }\end{array}$ & 32 & 0 & 15 & $68.1 \%$ & $0.0 \%$ & $31.9 \%$ \\
\hline $\begin{array}{l}\text { The cost of exercising prevents } \\
\text { me from exercising. }\end{array}$ & 33 & 3 & 11 & $70.2 \%$ & $6.0 \%$ & $23.4 \%$ \\
\hline $\begin{array}{l}\text { Small spaces prevent me from } \\
\text { exercising. }\end{array}$ & 36 & 3 & 8 & $76.6 \%$ & $6.0 \%$ & $17.0 \%$ \\
\hline
\end{tabular}

*D/SD: Disagree/Strongly disagree; NA/ND: Neither agree nor disagree; A/SA: Agree/Strongly agree

authors, the constant reassurance and encouragement encouragement involving family members and friends from an exercise instructor can make participants feel further supported by prior research studies done on the important and develop feelings of perseverance as well influence of social support on physical activity as confidence5. Additionally, receiving constant participation in other populations with physical encouragement from family and friends as a motivating disabilities such as adults with stroke, ${ }^{10}$ people with factor to increase exercise adherence among people with spinal cord injury,11 and people with arthritis. ${ }^{12}$ PD was consistent with a study done on the influence of Furthermore, the present study also highlighted the social support on physical activity participation among importance of experienced or expected positive physical seven active adults with early PD. ${ }^{9}$ One of the findings effects (feel healthier and more energetic) as well as the in this study was that emotional support provided by psychological effects (improves mood, gives a sense of family and friends can affect participants' decision to accomplishment, and feeling of control over PD) as participate in physical activity as well. The importance of facilitators for regular physical activity and exercise. 
The barriers reported by people with PD (ranked in order), were fatigue, weather, fear of falling, and lack of transportation. The most salient exercise barrier identified in this study was fatigue. Fatigue was reported to be a frequent, independent non-motor symptom in PD that appears early in the disease and persisting throughout the disease course that can result in worsening of quality of life. ${ }^{13}$ Due to the significant diminish in energy level experienced by people with PD, exercising may be more difficult for them when compared to normal healthy people. Fatigue has been reported as a significant barrier to exercise in several studies. ${ }^{7,4}$ Besides that, studies that established correlations between fatigue and reduced physical activity in people with PD have also been identified. However, due to the positive effects of exercise, fatigue should not hinder people with PD from exercise. ${ }^{14,15,16}$

Our study also reported the weather as an exercise barrier. This may be due to the tropical weather and frequent rainfalls experienced in Malaysia. Furthermore, the common mode of exercise among people with PD in this study was slow walks, which often require an outdoor environment. This further indicates the influence of weather when examining exercise participation in this population. Studies on the barriers to exercise in different populations have been done in Malaysia, some of which reported weather as one of the exercise barriers. The humid environment and heavy rains in Malaysia were reported as one of the factors in making exercising difficult for them. ${ }^{17}$ Besides that, studies have shown that adverse weather conditions such as cold, heat, or heavy rain can discourage older adults from participating in physical activity. ${ }^{18}$

Fear of falling was reported to be the third most common exercise barrier in this study. This may be because people with PD experience fear of falls more compared to elderly healthy individuals. ${ }^{19}$ Fear of falling has been described as an independent risk factor for falls in people with PD and has been associated with restriction of daily activities, loss of independence, and reduced quality of life. ${ }^{20}$ Therefore, it is important that fear of falling is specifically addressed. Interventions targeting fear of falling in older adults have included education about a realistic selfassessment of the risk of falling and environmental safety factors, risk-taking training to learn to seek assistance in situations in which they were fearful, and promotion of physical fitness. ${ }^{21}$

Lastly, lack of transportation was also reported as an exercise barrier among people with PD in this study which may be due to driving impairments in people with PD. Studies have shown that the driving ability of patients with even mild to moderate PD is impaired.22

\section{LIMITATION}

A limited sample of 47 people with PD from Kuala Lumpur and Selangor district in Malaysia represents a narrow sample. Secondly, all the participants are from the same non-governmental organisation which may deemed them to be motivated to specific exercises in that organization. Future research should include various representations throughout Malaysia.

\section{CLINICAL IMPLICATION}

Health professionals planning exercise interventions for this population should consider the identified exercise motivators and barriers to ensure efficient, effective, appropriate, and reasonable intervention programs for people with PD.

\section{CONCLUSION}

The study revealed that exercise motivators identified in this study were exercising with an exercise instructor and receiving constant encouragement from family members and friends.. Conversely, exercise barriers identified are fatigue, weather, fear of falling, and lack of transportation. Rehabilitators or health professionals can focus on these important factors on delivering efficient, effective, appropriate, and reasonable exercise intervention among people with PD.

\section{ACKNOWLEDGEMENT}

We would like to express our sincere gratitude to Malaysian Parkinson's Diseases Association for the continuous support rendered and thankful to all the fellow participants. 


\section{CONFLICT OF INTEREST}

No conflict of interest.

\section{DISCLOSURE STATEMENT}

No author has any financial interest or received any financial benefit from this research.

\section{REFERENCE}

1. Afshari M, Yang A, Bega D. Motivators and Barriers to Exercise in Parkinson's disease. J Parkinson's Dis. 2017; 7(4):703-711.

2. Rossi A, Torres-Panchame R, Gallo PM, Marcus AR, States RA. What makes a group fitness program for people with Parkinson's disease endure? A mixed-methods study of multiple stakeholders. Complement Ther Med. 2018 Dec; 41:320-327.

3. Eriksson BM, Arne M, Ahlgren C. Keep moving to retain the healthy self: the meaning of physical exercise in individuals with Parkinson's disease. Disabil Rehabil. 2013; 35(26):2237-44.

4. O'Brien C, Clemson L, Canning CG. Multiple factors, including non-motor impairments, influence decision making with regard to exercise participation in Parkinson's disease: a qualitative enquiry. Disabil Rehabil. 2016; 38(5):472-81.

5. Alexander M. Crizzle \& Ian J. Newhouse. Themes Associated with Exercise Adherence in Persons with Parkinson's disease: A Qualitative Study, Occupational Therapy in Health Care. 2012; 26:2-3: 174-186.

6. Grubbs L, Carter J. The relationship of perceived benefits and barriers to reported exercise behaviors in college undergraduates. Fam Community Health. 2002; Jul; 25(2):76-84.

7. Ellis T, Boudreau JK, DeAngelis TR, Brown LE, Cavanaugh JT, Earhart GM, Ford MP, Foreman $\mathrm{KB}$, Dibble LE. Barriers to exercise in people with Parkinson disease. Phys Ther. 2013 May; 93 (5):628-36.

8. Khalil H, Nazzal M, Al-Sheyab N. Parkinson's disease in Jordan: Barriers and motivators to exercise. Physiother Theory Pract. 2016 Oct; 32 (7):509-19.
9. Ravenek MJ, Schneider MA. Social support for physical activity and perceptions of control in early Parkinson's disease. Disabil Rehabil. 2009; 31(23):1925-36.

10. Damush TM, Plue L, Bakas T, Schmid A, Williams LS. Barriers and facilitators to exercise among stroke survivors. Rehabil Nurs. 2007 Nov -Dec; 32(6):253-60, 262.

11. Wahman Kerstin, Biguet Gabriele \& Levi Richard. What promotes physical activity after spinal cord injury? An interview study from a patient perspective, Disability and Rehabilitation, 2006. 28:8, 481-488.

12. Der Ananian C, Wilcox S, Saunders R, Watkins $\mathrm{K}$, Evans A. Factors that influence exercise among adults with arthritis in three activity levels. Prev Chronic Dis. 2006 Jul; 3(3): A81.

13. Siciliano M, Trojano L, Santangelo G, De Micco R, Tedeschi G, Tessitore A. Fatigue in Parkinson's disease: A systematic review and meta-analysis. Mov Disord. 2018 Nov; 33 (11):1712-1723.

14. Müller B, Assmus J, Herlofson K, Larsen JP, Tysnes OB. Importance of motor vs. non-motor symptoms for health-related quality of life in early Parkinson's disease. Parkinsonism Relat Disord. 2013 Nov; 19(11):1027-32.

15. Abrantes AM, Friedman JH, Brown RA, Strong DR, Desaulniers J, Ing E, Saritelli J, Riebe D. Physical activity and neuropsychiatric symptoms of Parkinson disease. J Geriatr Psychiatry Neurol. 2012 Sep; 25(3):138-45.

16. Garber, C. E., \& Friedman, J. H. Effects of fatigue on physical activity and function in patients with Parkinson's disease. Neurology. 2003 60(7), 1119-1124.

17. Hanlon C, Khoo S, Morris T, Eime R. Factors influencing women in physical activity programs in Malaysia. Health Promot Int. 2019 Jun 1; 34 (3):389-399.

18. Purath J, Van Son C, Corbett CF. Physical activity: exploring views of older Russianspeaking slavic immigrants. Nursing research and practice. 2011

19. Adkin AL, Frank JS, Jog MS. Fear of falling and postural control in Parkinson's disease. Mov Disord. 2003 May; 18(5):496-502. 
20. Nilsson, M.H., Drake, A. \& Hagell, P.

Assessment of fall-related self-efficacy and activity avoidance in people with Parkinson's disease. BMC Geriatr 2010 10, 78.

21. Legters K. Fear of falling. Phys Ther. 2002 Mar; 82(3):264-72.

22. Heikkilä VM, Turkka J, Korpelainen J, Kallanranta T, Summala H. Decreased driving ability in people with Parkinson's disease. J Neurol Neurosurg Psychiatry. 1998 Mar; 64 (3):325-30. 